Research Article

\title{
Risk Factors Associated with Overweight and Obesity in Japanese-Brazilians
}

\author{
Ivi R. Back $\left(\mathbb{D},{ }^{1}\right.$ Rosana R. Oliveira $\mathbb{D D}^{2}$ Eraldo S. Silva, ${ }^{3}$ and Sonia S. Marcon ${ }^{2}$ \\ ${ }^{1}$ Program in Health Sciences, State University of Maringá, 87.020-900 Maringá, PR, Brazil \\ ${ }^{2}$ Department of Nursing, State University of Maringá, 87.020-900 Maringá, PR, Brazil \\ ${ }^{3}$ Program in Biostatistics, State University of Maringá, 87.020-900 Maringá, PR, Brazil
}

Correspondence should be addressed to Ivi R. Back; iviback@hotmail.com

Received 24 January 2018; Accepted 15 April 2018; Published 8 May 2018

Academic Editor: Michael B. Zemel

Copyright (C) 2018 Ivi R. Back et al. This is an open access article distributed under the Creative Commons Attribution License, which permits unrestricted use, distribution, and reproduction in any medium, provided the original work is properly cited.

Objective. To estimate which risk factors (sociodemographic, lifestyle, and health conditions) are associated with overweight and obesity in Japanese-Brazilians. Methods. This was a cross-sectional study carried out with Japanese-Brazilians living in the southern region of Brazil. Data were collected between March and December of 2016 through a household survey addressing sociodemographic characteristics, lifestyle, and health conditions. Data were analyzed by means of logistic regression considering 95\% level of significance. Results. A total of 542 Japanese-Brazilians with a mean age of 47.75 years were evaluated; $52.8 \%$ were eutrophic, $36.9 \%$ were overweight, and $10.3 \%$ were people with obesity. The following variables remained associated with overweight after adjustments; male gender $(\mathrm{ORaj}=1.85, \mathrm{CI}=1.24-2.76)$, age range of 40-49 years $(\mathrm{ORaj}=2.27, \mathrm{CI}=1.10-4.68)$, and 50 to 59 years $(\mathrm{ORaj}=2.17, \mathrm{CI}=1.004-4.72)$, alcohol consumption $(\mathrm{ORaj}=2.11, \mathrm{CI}=1.07-4.16)$, and presence of chronic disease $(\mathrm{ORaj}=1.59, \mathrm{CI}=1.02-2.46)$. The following were independent factors associated with obesity: male gender $(\mathrm{ORaj}=3.63$, $\mathrm{CI}=1.78-7.40)$, the presence of chronic disease $(\mathrm{ORaj}=4.13, \mathrm{CI}=1.96-8.71)$, the age range of 30 to 39 years $(\mathrm{ORaj}=4.74$, $\mathrm{CI}=1.65-13.64)$ and 40 to 49 years $(\mathrm{ORaj}=2.89, \mathrm{CI}=1.05-7.95)$, and irregularly active lifestyle $(\mathrm{ORaj}=2.73, \mathrm{CI}=1.12-6.69)$. Conclusion. The results of this study show that being a male in the age range of 30-49 years old, alcohol consumption, and presence of chronic disease are associated with overweight and obesity in Japanese-Brazilians.

\section{Introduction}

Overweight has become a serious public health problem in many countries and is associated with chronic diseases such as metabolic syndrome, hypertension, and diabetes mellitus [1]. The increase in the number of adults who were overweight or with obesity (body mass index-BMI $\geq 25 \mathrm{~kg} / \mathrm{m}^{2}$ ) is alarming. The prevalence of obesity has doubled in more than 70 countries since 1980; 603.7 million adults worldwide will be with obesity by 2015 [2].

Thus, identifying the prevalence and factors associated with overweight and obesity has become the goal of many studies [1-4] since the obesity epidemic has been expanding globally. A study conducted in 31 countries including 20 in Europe, 8 in Asia, and Australia, Chile, and the USA reports the prevalence of overweight individuals and with obesity of $31.7 \%$ and $12.4 \%$, respectively [3].
Although obesity is a chronic and multifactorial disease, genetic and environmental factors must also be considered, which are reflected in specific populations with high or low rates $[3,5]$ as well as in some ethnic groups that denote more or fewer risks [5].

The National Nutrition Survey in Japan conducted in 2015 showed $18.9 \%$ overweight prevalence in women and $28 \%$ in men (BMI $>25 \mathrm{~kg} / \mathrm{m}^{2}$ ). In Brazil, studies have found higher rates of overweight and obesity in Japanese-Brazilians than those in Japan [4, 6, 7]. Overweight ranged from $34.5 \%$ in Curitiba in Paraná State [4] to $45.63 \%$ in Bauru in São Paulo State [7]. Another more specific study reported that out of the 1,581 Japanese-Brazilians evaluated in Bauru, 36.2\% were overweight and $8.7 \%$ were already with obesity [6].

In addition to the prevalence, the knowledge about risk factors that may be associated with overweight and obesity can subsidize the implementation of measures aimed at 
sensitizing this population about the importance of some behaviors and of prophylactic and sensitization procedures. Awareness about these associations can be useful to prevent overweight and obesity; these associations are still not clear and well-delimited.

Therefore, the objective of this study was to estimate the risk factors associated with overweight and obesity in Japanese-Brazilians.

\section{Materials and Methods}

2.1. Participants $x$ Sampling. This was a cross-sectional study using a household survey conducted in the city of Maringá in Paraná State, where one of the largest Japanese immigrant descents communities lives in Brazil. The study included Japanese-Brazilians of both genders and age equal to or older than 18 years and excluded individuals with physical disabilities and pregnant and breastfeeding women.

The Nikkei Census conducted in the municipality between 2008 and 2009 was used to calculate the sample size. This census identified a population of 14,324 Japanese-Brazilians; individuals; prevalence of $0.4 \%$ a overweight in the study population [4, 7]; with 95\% confidence level $(z=1.96)$ and a sample error of $4 \%(e=0.04)$ resulting in a sample size calculated as 576 , which added by $5 \%$ for possible losses resulted in a total of 603 individuals.

The selection of participants was based on information from the Nikkei Census, which showed similarities between the urban and living conditions of Japanese-Brazilians (housing, infrastructure, sanitation, education, health services, and educational level). This allowed grouping neighborhoods in seven continuous regions (stratum). Subsequently, these participants were randomly picked, proportionally to the total number of Japanese-Brazilians residents in each stratum.

Those who were drawn were located based on the addresses listed in the Nikkei census or indication from other Japanese-Brazilian residents in the same stratum. Those not located after three visits conducted on different days and different times, as well as those who refused to participate in the study, were replaced by individuals residing in the same stratum in order to maintain the total sample and stratum sizes. It is noteworthy that a total of 150 replacements were performed and that subjects with low weight $(n=61)$ were excluded from the present analysis.

2.2. Procedures and Study Variables. The data were collected from March to December of 2016 through a semistructured interview and the use of a questionnaire addressing sociodemographic characteristics, lifestyle, and health conditions. The sociodemographic variables were gender, generation of immigrants (issei: Japanese immigrants; nisei: children of immigrants; sansei: grandchildren of immigrants; and yonsei: great grandchildren of immigrants) [8], age, marital status (with partner/without partner), educational level (illiterate; elementary/incomplete middle; middle/incomplete high school; high school/incomplete college; college), and purchasing power. Purchasing pocalculation of the Brazilian Association of Companies and Research-ABEP [9].
The variables related to lifestyle were (a) self-referred diet: good, fair, and poor as proposed in the Ministry of Health's Food Guide [10]; (b) daily consumption of fruits: consumes-three or more portions, unsatisfactory-one or two portions, no consumption; (c) daily consumption of vegetables: consumes - three or more portions, unsatisfactory-one or two portions, no consumption; (d) alcohol consumption: no consumption, low-risk consumption, and risky consumption [11]; (e) smoking: classified as low level, elevated, and nonsmoking [12], and (f) practice of physical activity: active, irregularly active, and sedentary [13].

The evaluation of health conditions included: (a) selfperception of health: classified as excellent, very good, good, fair, and poor; (b) the presence of chronic autoreferred diseases: yes/no. At the time of the interview, the blood pressure was verified in a Premium ${ }^{\circledR}$ aneroid pressure device, with a cuff suitable for the brachial perimeter, individual sitting, uncrossed legs, feet resting on the floor, right arm resting on the heart, after three to five minutes of rest. At least two checks were performed, with an interval of one minute between them. A third measurement was performed when the first two were very different. The mean of the two measurements was considered to be the nearest. The blood pressure value was classified as altered when systolic blood pressure (SBP) $\geq 140$ and/or diastolic blood pressure (DBP) $\geq 90$ [14].

Weight and height were measured for the evaluation of the nutritional status according to age: (a) $\geq 60$ years: low weight $\left(<22 \mathrm{~kg} / \mathrm{m}^{2}\right)$, eutrophic $\left(22-27 \mathrm{~kg} / \mathrm{m}^{2}\right)$, and overweight $\left(27 \mathrm{~kg} / \mathrm{m}^{2}\right)[15]$; (b) $\geq 20-\leq 59$ years: low weight $\left(<18.5 \mathrm{~kg} / \mathrm{m}^{2}\right)$; eutrophic (18.5-24.9 kg/m $\left.{ }^{2}\right)$; overweight $\left(25-29.9 \mathrm{~kg} / \mathrm{m}^{2}\right)$; and obese $\left(>30 \mathrm{~kg} / \mathrm{m}^{2}\right)$ [16]; (c) $\leq 19$ years: low weight (percentile 3 ); eutrophic (percentile $\geq 3$-<percentile 85 ); overweight ( $\geq$ percent $85-<$ percentile 97 ); obese ( $\geq$ percentile 97$)[17,18]$.

2.3. Statistical Analysis. Data were entered and organized in Microsoft Excel worksheets and later analyzed using the Statistical Analysis Software (SAS, Version 9.3).

Univariate logistic regression was performed to verify the risks for overweight and obesity in relation to eutrophy. All variables with $p$ value $<0.20$ in the univariate analysis were included in the multiple logistic regression analysis. Those with $p$ value $<0.05$ remained in the final model; variables that acted as adjustments were identified. A significance level of $95 \%$ was considered.

2.4. Ethical Precepts. All participants were informed about the objectives of the study and type of participation desired and signed the free and informed consent term. The project was approved by the Committee on Ethics in Research with Human Beings of the Maringá State University (Opinion $n^{\circ} 1$ 150 115/2015).

\section{Results}

A total of 542 Japanese-Brazilians aged 18-87 years (mean age 47.75 years \pm 18.14 ) were selected for this study; $52.8 \%$ were eutrophic, $36.9 \%$ were overweight, and $10.3 \%$ were with obesity. 
TABLE 1: Risk of overweight and obesity related to eutrophy in sociodemographic variables of Japanese-Brazilian individuals. Maringá-PR, Brazil, 2016.

\begin{tabular}{|c|c|c|c|c|c|c|c|c|c|}
\hline \multicolumn{10}{|c|}{ BMI-Brazil } \\
\hline Variables & $\begin{array}{l}\text { Eutrophic } \\
n(\%) 286\end{array}$ & $\begin{array}{l}\text { Overweight } \\
n(\%) 200\end{array}$ & $\begin{array}{l}\text { Odds } \\
\text { ratio }\end{array}$ & CI (95\%) & $p$ value & $\begin{array}{c}\text { With } \\
\text { obesity } \\
n(\%) 56\end{array}$ & $\begin{array}{l}\text { Odds } \\
\text { ratio }\end{array}$ & CI $(95 \%)$ & $\begin{array}{c}p \\
\text { value }\end{array}$ \\
\hline \multicolumn{10}{|l|}{ Gender } \\
\hline Female & $180(62.94)$ & $88(44.00)$ & & - & & $20(35.71)$ & & - & \\
\hline Male & $106(37.06)$ & $112(56.00)$ & 2.161 & $1.49-3.12$ & $<0.0001$ & $36(64.29)$ & 3.057 & $1.68-5.55$ & $<0.0001$ \\
\hline \multicolumn{10}{|c|}{ 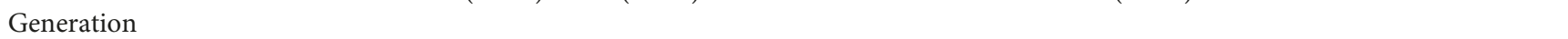 } \\
\hline Isei & $10(3.50)$ & $3(1.50)$ & & - & & 0 & & - & \\
\hline Nisei & $128(44.76)$ & $98(49.00)$ & 2.55 & $0.68-9.52$ & 0.163 & $16(28.57)$ & $>999$ & $<0.001-999$ & 0.957 \\
\hline Sansei & $121(42.31)$ & $90(45.00)$ & 2.47 & $0.66-9.26$ & 0.177 & $36(64.29)$ & $>999$ & $<0.001-999$ & 0.953 \\
\hline Yonsei & $27(9.44)$ & $9(4.50)$ & 1.11 & $0.24-4.95$ & 0.890 & $4(7.14)$ & $>999$ & $<0.001-999$ & 0.956 \\
\hline \multicolumn{10}{|l|}{ Age range } \\
\hline 1 to 29 years & $82(28.67)$ & $31(15.50)$ & & - & & $8(14.29)$ & & - & \\
\hline 30 to 39 years & 30 (10.49) & $19(9.50)$ & 1.67 & $0.82-3.40$ & 0.15 & $16(28.57)$ & 5.46 & $2.12-14.08$ & $<0.0001$ \\
\hline 40 to 49 years & $40(13.99)$ & $46(23.00)$ & 3.04 & $1.68-5.49$ & $<0.001$ & 15 (26.79) & 3.84 & $1.50-9.81$ & 0.005 \\
\hline 50 to 59 years & $35(12.24)$ & $40(20.00)$ & 3.02 & $1.63-5.58$ & $<0.001$ & $17(30.36)$ & 4.97 & $1.96-12.60$ & 0.001 \\
\hline 60 or + & $99(34.62)$ & $64(32.00)$ & 1.71 & $1.01-2.87$ & 0.04 & 0 & 0.00 & 0.000 & 0.99 \\
\hline \multicolumn{10}{|l|}{ Financial status } \\
\hline A & $77(26.92)$ & $66(33.00)$ & & - & & $12(21.43)$ & & - & \\
\hline $\mathrm{B} 1$ & $86(30.07)$ & $60(30.00)$ & 0.81 & $0.51-1.29$ & 0.386 & $19(33.93)$ & 1.417 & $0.64-3.10$ & 0.383 \\
\hline B2 & $98(34.27)$ & $63(31.50)$ & 0.75 & $0.47-1.18$ & 0.216 & $19(33.93)$ & 1.244 & $0.56-2.71$ & 0.584 \\
\hline $\mathrm{C} 1$ & $16(5.59)$ & $10(5.00)$ & 0.72 & $0.31-1.71$ & 0.469 & $4(7.14)$ & 1.604 & $0.45-5.61$ & 0.459 \\
\hline $\mathrm{C} 2-\mathrm{D}$ & $9(3.15)$ & $1(0.50)$ & 0.13 & $0.01-1.05$ & 0.05 & $2(3.57)$ & 1.426 & $0.27-7.41$ & 0.673 \\
\hline \multicolumn{10}{|l|}{ Education } \\
\hline Illiterate & $8(2.80)$ & $1(0.50)$ & 0.15 & $0.01-1.23$ & 3.116 & $3(5.36)$ & 2.054 & $0.50-8.37$ & 0.315 \\
\hline Elementary/incomplete middle & $27(9.44)$ & $19(9.50)$ & 0.85 & $0.44-1.62$ & 0.236 & 0 & $<0.001$ & $<0.001-999$ & 0.968 \\
\hline Middle/incomplete high school & $32(11.19)$ & $19(9.50)$ & 0.71 & $0.38-1.34$ & 1.057 & $3(5.36)$ & 0.513 & $0.14-1.83$ & 0.304 \\
\hline High school/incomplete college & $104(36.36)$ & $66(33.00)$ & 0.76 & $0.50-1.15$ & 1.580 & $29(51.79)$ & 1.52 & $0.82-2.84$ & 0.181 \\
\hline College & $115(40.21)$ & $95(47.50)$ & & - & & $21(37.50)$ & & - & \\
\hline \multicolumn{10}{|l|}{ Marital status } \\
\hline With a partner & $156(54.55)$ & $140(70.00)$ & 1.94 & $1.32-2.84$ & 0.001 & $36(64.29)$ & 1.500 & $0.82-2.71$ & 0.18 \\
\hline Without a partner & $130(45.45)$ & $60(30.00)$ & & - & & $20(35.71)$ & & - & \\
\hline \multicolumn{10}{|l|}{ Professional status } \\
\hline Retired & $61(21.3)$ & $39(19.50)$ & 0.84 & $0.51-1.39$ & 0.50 & $2(3.60)$ & 0.23 & $0.51-1.05$ & 0.05 \\
\hline Self-employed & $53(18.5)$ & $56(28.00)$ & 1.39 & $0.86-2.25$ & 0.17 & $27(48.20)$ & 3.60 & $1.74-7.45$ & 0.001 \\
\hline Home maker & $26(9.1)$ & $15(7.5)$ & 0.76 & $0.37-1.53$ & 0.44 & $7(12.50)$ & 1.90 & $0.69-5.20$ & 0.20 \\
\hline Working & $99(34.6)$ & $75(37.5)$ & & - & & $14(25.00)$ & & - & \\
\hline Student & $47(16.4)$ & $15(7.5)$ & 0.42 & $0.21-0.81$ & 0.01 & $6(10.70)$ & 0.90 & $0.32-2.49$ & 0.84 \\
\hline
\end{tabular}

Most of the women presented eutrophy (62.5\%), 30.6\% were overweight, and $6.9 \%$ were with obesity. A large portion of men was overweight (44.1\%), $41.7 \%$ were eutrophic, and $14.2 \%$ were with obesity.

Thus, in relation to women, men presented a significant risk of being overweight (ODDS: 2.161, CI: 1.49-3.12; $p<0.001$ ) and with obesity (ODDS: 3,057; CI: 1.68-5.55; $p<0.001)$ compared to the eutrophic condition; this risk was double for overweight and triple for obesity.

The odds of being overweight and with obesity were significantly higher as age increased; the chance of being overweight was three times higher in the age range between 30 and 49 years $(p<0.001)$ and almost five times higher $(p<0.001)$ in the age range between 50 and 59 years compared to the other age ranges. The odds of individuals with partners of being overweight were almost twice higher than individuals without partners $(p<0.001)$.

Regarding professional activities, self-employed individuals showed a 3.60 -fold higher chance of being with obesity ( $p=0.001)$ than those in other professions; being a student was a protective factor for the overweight condition $(p=0.01)$. Table 1 shows other associations between overweight and obesity and sociodemographic variables.

Table 2 shows that the chance of irregularly active individuals presenting obesity was almost twice as high as those with sedentary behavior among eutrophics. The odds of being overweight and obesity were respectively three and four times higher than those with sedentary behavior among those who consumed alcohol. Those with poor eating habits were three times more likely to be with obesity compared to those in other groups. Likewise, those who did not consume or had unsatisfactory consumption of fruits were at least three times more likely to be with obesity compared to those who consumed fruits.

The distribution of health conditions among participants was $15.3 \%$ diabetes mellitus, $46.7 \%$ hypertension, $23.6 \%$ hypercholesterolemia, 3.1\% kidney problems, 3.7\% cancer, $4.4 \%$ cardiovascular disease, and $1.5 \%$ stroke. Those with 
TABLE 2: Risk of overweight and obesity related to eutrophy and lifestyle and health conditions of Japanese-Brazilians in the city of Maringá-PR, Brazil, 2016.

\begin{tabular}{|c|c|c|c|c|c|c|c|c|c|}
\hline Variables & $\begin{array}{c}\text { Eutrophic } \\
n(\%)\end{array}$ & $\begin{array}{c}\text { Overweight } \\
n(\%)\end{array}$ & $\begin{array}{l}\text { Odds } \\
\text { ratio }\end{array}$ & CI (95\%) & $p$ value & $\begin{array}{c}\text { With } \\
\text { obesity } \\
n(\%)\end{array}$ & $\begin{array}{l}\text { Odds } \\
\text { ratio }\end{array}$ & CI $(95 \%)$ & $p$ value \\
\hline \multicolumn{10}{|l|}{ Lifestyle } \\
\hline \multicolumn{10}{|l|}{ Tobacco use } \\
\hline Low & $4(1.40)$ & $6(3.00)$ & 2.21 & $0.61-7.96$ & 0.22 & $5(8.93)$ & 6.95 & $1.80-26.77$ & 0.005 \\
\hline Elevated & $4(1.40)$ & $6(3.00)$ & 2.21 & $0.61-7.96$ & 0.22 & $1(1.79)$ & 1.39 & $0.15-12.69$ & 0.77 \\
\hline Nonsmoker & $278(97.20)$ & $188(94.0)$ & & - & & $50(89.29)$ & & - & \\
\hline \multicolumn{10}{|l|}{ Physical activity } \\
\hline Active & $77(26.92)$ & $53(26.50)$ & & - & & $11(19.64)$ & & - & \\
\hline Irregularly active & $120(41.96)$ & $92(46.00)$ & 1.11 & $0.71-1.73$ & 0.63 & $34(60.71)$ & 1.98 & $0.94-4.14$ & 0.06 \\
\hline Sedentary & $89(31.12)$ & $55(27.50)$ & 0.89 & $0.55-1.45$ & 0.63 & $11(19.64)$ & 0.86 & $0.35-2.10$ & 0.74 \\
\hline \multicolumn{10}{|l|}{ Alcohol consumption } \\
\hline Does not consume & $176(61.5)$ & $95(47.5)$ & & - & & $24(42.9)$ & & - & \\
\hline Low-risk consumption & $92(32.2)$ & $74(37.0)$ & 1.49 & $1.00-2.21$ & 0.048 & $22(39.3)$ & 1.74 & $0.93-3.29$ & 0.081 \\
\hline Risky consumption & $18(6.3)$ & $31(15.5)$ & 3.19 & $1.69-6.00$ & 0.000 & $10(17.9)$ & 4.07 & $1.68-9.85$ & 0.002 \\
\hline \multicolumn{10}{|l|}{ Eating habits } \\
\hline Regular & $201(70.28)$ & $148(74.00)$ & 1.32 & $0.83-2.10$ & 0.23 & $37(66.07)$ & 1.28 & $0.59-2.81$ & 0.524 \\
\hline Bad & $22(7.69)$ & $17(8.50)$ & 1.39 & $0.65-2.96$ & 0.39 & $10(17.86)$ & 3.18 & $1.14-8.85$ & 0.026 \\
\hline Good & $63(22.03)$ & $35(17.50)$ & & - & & $9(16.07)$ & & - & \\
\hline \multicolumn{10}{|l|}{ Fruit consumption } \\
\hline Consumer & $87(30.4)$ & $59(29.50)$ & & - & & $6(10.7)$ & & - & \\
\hline Not satisfactory & $151(62.8)$ & $112(56.00)$ & 1.09 & $0.72-1.65$ & 0.66 & $37(23.2)$ & 3.55 & $1.44-8.75$ & 0.006 \\
\hline Does not consume & $48(16.8)$ & $29(14.5)$ & 0.89 & $0.50-1.57$ & 0.69 & $13(16.4)$ & 3.92 & $1.40-10.99$ & 0.009 \\
\hline \multicolumn{10}{|l|}{ Vegetable consumption } \\
\hline Consumer & $228(79.7)$ & $166(83.00)$ & & - & & $42(75.00)$ & & - & \\
\hline Not satisfactory & $49(17.10)$ & $23(11.50)$ & 0.10 & $0.37-1.10$ & 0.64 & $10(17.90)$ & 1.10 & $0.52-2.35$ & 0.79 \\
\hline Does not consume & $9(3.10)$ & $11(5.50)$ & 0.26 & $0.68-4.14$ & 0.68 & $4(7.10)$ & 2.41 & $0.71-8.19$ & 0.15 \\
\hline \multicolumn{10}{|l|}{ Health conditions } \\
\hline \multicolumn{10}{|l|}{ Blood pressure alteration } \\
\hline Altered & $100(34.97)$ & $112(56.0)$ & 2.36 & $1.63-3.42$ & $<0.001$ & $41(73.21)$ & 5.08 & $2.68-9.63$ & $<0.001$ \\
\hline Not altered & $186(65.03)$ & $88(44.00)$ & & - & & $15(26.79)$ & & - & \\
\hline \multicolumn{10}{|l|}{ Chronic disease* } \\
\hline \multicolumn{10}{|l|}{ Self-referred } \\
\hline No & $174(60.84)$ & $95(47.50)$ & & - & & $24(42.86)$ & & - & \\
\hline Yes & $112(39.16)$ & $105(52.50)$ & 1.72 & $1.19-2.47$ & 0.004 & $32(57.14)$ & 2.07 & $1.16-3.70$ & 0.014 \\
\hline \multicolumn{10}{|l|}{ Health self-perception } \\
\hline Excellent & $43(15.00)$ & $33(16.50)$ & & - & & $7(12.50)$ & & - & \\
\hline Very good & $73(25.50)$ & $33(16.50)$ & 0.62 & $0.33-1.15$ & 0.13 & $6(10.70)$ & 0.50 & $0.15-1.60$ & 0.24 \\
\hline Good & $133(46.50)$ & $93(46.50)$ & 0.94 & $0.55-1.59$ & 0.94 & $30(53.60)$ & 1.38 & $0.56-3.38$ & 0.47 \\
\hline Regular & $34(11.90)$ & $35(17.50)$ & 1.38 & $0.71-2.66$ & 1.38 & $8(14.30)$ & 1.44 & $0.47-4.38$ & 0.51 \\
\hline $\mathrm{Bad}$ & $3(1.00)$ & $6(3.00)$ & 2.68 & $0.62-11.56$ & 2.68 & $5(8.90)$ & 10.23 & $1.98-52.73$ & 0.005 \\
\hline
\end{tabular}

*The following were considered chronic diseases: diabetes, hypertension, hypercholesterolemia, cancer, and kidney and heart problems.

self-reported chronic diseases (diabetes mellitus, hypertension, hypercholesterolemia, cancer, kidney and heart issues, and stroke) showed chances for being overweight and obesity increased by almost two-fold compared to eutrophic individuals (Table 2). It was also observed that presenting altered blood pressure doubles the chances of being overweight, and quintuple the chances of being with obesity.

The multivariate logistic regression analysis for being overweight after adjusting for marital status showed that being a male between 40 and 59 years old and consuming alcoholic beverages almost doubles the chance of being overweight. Moreover, the presence of some type of chronic disease was associated with being overweight (Table 3).

Conversely, the multivariate logistic regression analysis for obesity demonstrated that being male or presenting some type of chronic disease increases the chance of obesity by almost four times. The age group of young adults between 30 and 49 years of age presented associations with obesity. Regarding the practice of physical activity, being irregularly active almost tripled the chances of obesity (Table 3).

\section{Discussion}

The prevalence of overweight individuals in immigrants is already the focus of several studies. However, data on associations between some risk factors such as lifestyle, health conditions, and sociodemographic characteristics and overweight and obesity in Japanese-Brazilians are still scarce. In this study, a significant association was observed after adjustments between overweight and obesity in young male 
TABLE 3: Logistic regression of factors associated with overweight and obesity in Japanese-Brazilians living in Maringá-PR, Brazil, 2016.

\begin{tabular}{|c|c|c|c|}
\hline Variables & $\begin{array}{c}\text { Odds ratio } \\
\text { (ORaj) }\end{array}$ & CI $(95 \%)$ & $p$ value \\
\hline \multicolumn{4}{|l|}{ Overweight* } \\
\hline \multicolumn{4}{|l|}{ Gender $^{\circ}$} \\
\hline Female & - & - & - \\
\hline Male & 1.857 & $1.24-2.76$ & 0.002 \\
\hline \multicolumn{4}{|l|}{ Age range } \\
\hline 1 to 29 years & - & - & \\
\hline 30 to 39 years & 1.397 & $0.65-2.99$ & 0.389 \\
\hline 40 to 49 years & 2.275 & $1.10-4.68$ & 0.026 \\
\hline 50 to 59 years & 2.177 & $1.004-4.72$ & 0.049 \\
\hline 60 or + & 1.128 & $0.56-2.25$ & 0.734 \\
\hline \multicolumn{4}{|l|}{ Marital status } \\
\hline With a partner & 1.162 & $0.69-1.93$ & 0.563 \\
\hline Without a partner & - & - & - \\
\hline \multicolumn{4}{|l|}{ Alcohol consumption } \\
\hline Does not consume & - & - & - \\
\hline Low-risk consumption & 1.417 & $0.93-2.14$ & 0.099 \\
\hline Risky consumption & 2.110 & $1.07-4.16$ & 0.031 \\
\hline \multicolumn{4}{|c|}{ Chronic disease $^{\#}$ (self-referred) } \\
\hline No & - & - & - \\
\hline Yes & 1.592 & $1.02-2.46$ & 0.037 \\
\hline \multicolumn{4}{|l|}{ With obesity } \\
\hline \multicolumn{4}{|l|}{ Gender } \\
\hline Female & - & - & - \\
\hline Male & 3.633 & $1.78-7.40$ & $<0.001$ \\
\hline \multicolumn{4}{|l|}{ Chronic disease } \\
\hline Yes & 4.139 & $1.96-8.71$ & $<0.001$ \\
\hline No & - & - & - \\
\hline \multicolumn{4}{|l|}{ Age range } \\
\hline 1 to 29 years & - & - & - \\
\hline 30 to 39 years & 4.746 & $1.65-13.64$ & 0.004 \\
\hline 40 to 49 years & 2.898 & $1.05-7.95$ & 0.039 \\
\hline 50 to 59 years & 2.335 & $0.79-6.84$ & 0.122 \\
\hline 60 or + & 0.000 & 0.000 & 0.996 \\
\hline \multicolumn{4}{|l|}{ Physical activity } \\
\hline Active & - & - & - \\
\hline Irregularly active & 2.737 & $1.12-6.69$ & 0.027 \\
\hline Sedentary & 0.851 & $0.30-2.36$ & 0.757 \\
\hline
\end{tabular}

* Model adjusted for marital status and low-risk alcohol consumption. ${ }^{*}$ The following were considered chronic diseases: diabetes, hypertension, hypercholesterolemia, cancer, and kidney and heart problems.

adults (between 30 and 59 years) and the presence of chronic diseases. Moreover, individuals who consume alcoholic beverages are more likely to be overweight, and those who irregularly practice physical activities showed increased risks for obesity.

Population studies show that the incidence of overweight and obesity is increasing worldwide [1-3]. JapaneseBrazilians are probably included in this scenario as a consequence of Westernization in their life habits [4]; some studies with this specific population $[4,6,19]$ report high rates of overweight and obesity corroborating the process of acculturation.

In Brazil, the prevalence of overweight increased 11.2\% in 10 years, from $42.6 \%$ in 2006 to $53.8 \%$ in 2016 [20], while in Japan, the prevalence of overweight/obesity in 2015 was $23.1 \%$ [21]. The prevalence of overweight (overweight 36.9\% and obesity $10.3 \%$ ) identified in this study is closer to the prevalence in Brazil (53.8\%) than that in Japan (23.1\%) suggesting the influence of the process of acculturation to which immigrants are exposed.

The sociodemographic characteristics of the studied population show that men are almost twice as likely to be overweight (ORaj: 1.85, CI: 1.24-2.76), and almost four times more likely to be with obesity than women (ORaj: 3.63; CI: 1.78-7.40). These results reinforce results of other studies with Japanese-Brazilians [4, 22]. A study carried out in Bauru with 772 Japanese-Brazilians observes that the intake of fat and processed food were positively associated with obesity in men [19]. Thus, men are probably more vulnerable to risk factors to being overweight, which points to the need to broaden and deepen the gaze on gender differences to support adequate planning for coping and treatment of health conditions associated with excess weight.

The odds of being overweight are higher among individuals aged 40 to 49 years (ORaj: 2.27, CI: 1.10-4.68) and 50 to 59 years (ORaj: 2.17; IC: $1.004-4.72$ ) than at other age ranges. The odds of obesity are higher among individuals aged 30 to 39 years (ORaj: 4.74, CI: 1.65-13.64) and 40 to 49 (ORA: 2.89, CI: 1.05-7.95) than at other age ranges. These results differ from those reported in a study with a Spanish population including 21,007 adults reporting that the risk of overweight and obesity is higher in individuals aged over 74 years than in younger individuals [1]. Considering the differences between these two populations with regard to age structure and living conditions, which influence life expectancy, it is worth noting that overweight appears in that Spanish population in later decades compared to the studied Japanese-Brazilian population. Other studies with JapaneseBrazilians also report high overweight and obesity prevalence in young adults $[7,23]$. Therefore, this population needs to be sensitized and closely monitored by the health sector because individuals with obesity are three to four times more likely to develop cardiometabolic problems compared to those at normal weight [24].

Our results show that individuals with chronic diseases are almost twice as likely to be overweight (ORaj: 1.59; CI: 1.02-2.46) and four times as likely to be with obesity (ORaj: 4, 13, CI: 1.96-8.71) than individuals without chronic diseases. A study carried out in Bauru in Brazil with 1,030 Japanese-Brazilians shows high rates of chronic diseases distributed as $45.4 \%$ hypertension, $34.9 \%$ diabetes mellitus, 62.2\% hypercholesterolemia, $64.3 \%$ increased triglycerides, and $21.1 \%$ peripheral arterial obstructive disease [22]. Those authors suggest that these results reflect the exposure to a westernized environment, which exacerbates the genetic tendency to accumulate body fat. The different results observed in the present study (15.3\% diabetes mellitus, $46.7 \%$ hypertension, and $23.6 \%$ hypercholesterolemia) might be due to the use of different methodologies to diagnose these chronic diseases; these diseases were self-reported in this study and diagnosed through laboratory exams in that study.

A significant increase in the prevalence of chronic diseases has been observed in Brazil in the last decade (61.8\% of diabetes and $14.2 \%$ of hypertension) [20]. Despite the increased prevalence among Brazilians, the tendency to 
present chronic diseases in the studied population is similar to that reported in previous studies with Japanese-Brazilians $[6,22,25]$. Therefore, it is important to promote awareness among immigrant populations in maintaining a normal weight considering the number of benefits to the nondevelopment of chronic diseases. According to a study carried out in 195 countries with data from 68.5 million people in 2015, high BMI contributed to 4.0 million deaths [2].

In this sample, both low-risk consumption (ORaj: 1.417; CI: $0.93-2.14$ ) and high-risk consumption of alcoholic beverages were associated with overweight (ORaj: 2.11; CI: 1.07-4.16). A population-based study including 48,741,000 adults also observed an association between alcohol consumption and overweight; the study reports that alcohol consumption (several times a month) was associated with overweight in 31 evaluated countries (ORaj: 1.13 CI: 1.041.22) [3]. Therefore, the present study helps to clarify the complex relationship between alcohol consumption and obesity, particularly in the context of lifestyle behaviors and health conditions [26].

Individuals who practice physical activity irregularly in terms of frequency or duration are three times more likely to be with obesity (ORaj: 2.73; CI: 1.12-6.69). These findings differ from those reported in a study about behavioral risk factors performed in 31 countries reporting that physical inactivity was inversely associated with overweight but not associated with obesity [3]. Such findings are probably explained by the difference in criteria used to classify individuals as physically active or inactive. That study considered individuals who performed at least 20 minutes of daily, several times a week, or sometimes in a month of physical activity enough to break a sweat or breathe deeply as active. Our study considered the frequency (number of minutes performing a physical activity) and days (number of days per week) to estimate minutes\week of physical activity considering $>150$ minutes/week as the cutoff point to be classified as physically active. Physical activity contributes to energy consumption, prevents obesity, favors weight loss, and reduces the risk of developing cardiovascular diseases, type 2 diabetes mellitus, and some types of cancer [27].

It is important to emphasize that the design of this crosssectional study does not allow establishing a cause-effect relationship. However, the results increase the knowledge about the risk factors associated with the conditions of overweight and obesity in Japanese-Brazilians. Hence, considering the small number of studies on factors associated with overweight and obesity in Japanese-Brazilians, it is believed that our results can support the implementation of interventions aimed at weight control and consequently prevention of related diseases in this population.

\section{Conclusions}

The results of this study allow us to affirm that being male, age (30-49 years), alcohol consumption, and the presence of chronic disease are associated with overweight and obesity in Japanese-Brazilians. Thus, better planning and implementation of care would contribute to nutritional behavior and decrease the risk factors associated with overweight and obesity in this population.

\section{Data Availability}

The data used to support the findings of this study were provided under license, access to these data will be considered by any the authors and may be requested from the corresponding author.

\section{Conflicts of Interest}

The authors declare no conflicts of interest.

\section{References}

[1] M. Marqueta de Salas, J. Martín-Ramiro, and J. J. J. Soto, "Sociodemographic characteristics as risk factors for obesity and overweight in Spanish adult population," Medicina Clínica, vol. 146, no. 11, pp. 471-477, 2016.

[2] The GBD 2015 Obesity Collaborators, "Health effects of overweight and obesity in 195 countries over 25 years," New England Journal of Medicine, vol. 377, pp. 13-27, 2017.

[3] S. Pengpid and K. Peltzer, "Associations between behavioural risk factors and overweight and obesity among adults in population-based samples from 31 countries," Obesity Research and Clinical Practice, vol. 11, no. 2, pp. 158-166, 2017.

[4] A. O. Tamura, A. M. Fukui, S. A. H. Mochi, and I. M. I. Morimoto, "Social, nutritional, and feeding profile of Japanese and Japanese-Brazilian descendants from different generations," Brazilian Society for Food and Nutrition, vol. 38, no. 3, pp. 306-21, 2013.

[5] L. Wang, J. Southerland, K. Wang et al., "Ethnic differences in risk factors for obesity among adults in California, the United States," Journal of Obesity, vol. 2017, Article ID 2427483, 10 pages, 2017.

[6] M. R. Bevilacqua and S. G. A. Gimeno, "Abdominal obesity in Japanese-Brazilians: which measure is best for predicting allcause and cardiovascular mortality?," Cadernos de Saúde Pública, vol. 27, no. 10, pp. 1986-1996, 2011.

[7] R. F. Simony, S. G. Gimeno, S. R. G. Ferreira et al., "Prevalence of overweight and obesity among Japanese-Brazilian: comparison across sex and generation," Revista de Nutrição, vol. 21, no. 2, pp. 169-176, 2008.

[8] M. M. Roberge, "California's generation 1.5 immigrants: what experiences, characteristics, and need do they bring to our English classes?," The Catesol Journal, vol. 14, no. 1, pp. 107-129, 2002.

[9] Associação Brasileira de Empresas e Pesquisa, Critérios de Classificação Econômicas Brasil, October 2015, http://www. abep.org.

[10] Ministério da Saúde, Secretaria de Saúde. Guia Alimentar: Como ter Uma Alimentação Saudável, Ministério da Saúde, Brasília, DF, Brazil, 2012.

[11] C. Lima, A. C. C. Freire, A. P. B. Silva, R. M. Teixeira, M. Farrell, and M. Prince, "Concurrent and construct validity of the audit in an urban Brazilian sample," Alcohol and Alcoholism, vol. 40, no. 6, pp. 584-589, 2005.

[12] J. T. Carmo and A. A. Pueyo, "Adaptation into Portuguese for the Fagerström test for nicotine dependence (FTND) to evaluate the dependence and tolerance for nicotine in Brazilian smokers," Revista Brasileira De Medicina, vol. 59, no. 1-2, pp. 73-80, 2002. 
[13] S. Matsudo, A. Timoteo, V. Matsudo et al., "International physical activity questionnaire (LPAQ): study of validity and reliability in Brazil," Revista Brasileira de Atividade Física and Saúde, vol. 6, no. 2, pp. 5-18, 2001.

[14] M. V. B. Malachias, W. K. S. B. Souza, F. L. Plavnik et al., "7 $7^{\text {a }}$ Diretriz brasileira de hipertensão arterial," Arquivos Brasileiros de Cardiologia, vol. 107, no. 3, pp. 1-83, 2016.

[15] D. A. Lipschitz, "Screening for nutritional status in the elderly," Primary Care, vol. 21, no. 1, pp. 55-67, 1994.

[16] World Health Organization, Obesity: Preventing and Managing the Global Epidemic, WHO, Geneva, Switzerland, April 2017, http://apps.who.int/iris/handle/10665/42330.

[17] A. R. Frisancho, "New norms of upper limb fat and muscle areas for assessment of nutritional status," American Journal of Clinical Nutrition, vol. 34, no. 11, pp. 2540-2545, 1981.

[18] A. R. Frisancho, Anthropometric Standards for the Assessment of Growth and Nutritional Status, University of Michigan, Ann Arbor, MI, USA, 1990.

[19] M. F. Cristofoletti, S. G. A. Gimeno, S. R. G. Ferreira, and M. A. Cardoso, "Association of processed meat intake and obesity in a population-based study of Japanese-Brazilians," Arquivos Brasileiros de Endocrinologia and Metabologia, vol. 57, no. 6, pp. 464-472, 2013.

[20] Ministério da Saúde, Vigitel Brasil 2016: Vigilância de Fatores de Risco e Proteção para Doenças Crônicas por Inquérito Telefônico, Ministério da Saúde, Brasília, DF, Brazil, 2017.

[21] National Health and Nutrition Survey, August 2017, http:// www.mhlw.go.jp/seisakunitsuite/bunya/kenkou_iryou/kenkou/ kenkounippon21/en/eiyouchousa/koumoku_seikatsu_syuukan_ chousa.html.

[22] L. Garofolo, S. R. G. Ferreira, and F. Miranda Junior, "Study of risk factors associated with peripheral arteriopathy in Japanese-Brazilians from Bauru (SP)," Arquivos Brasileiros de Cardiologia, vol. 102, no. 2, pp. 143-150, 2014.

[23] P. M. Gomes, R. C. G. Andrade, R. C. Figueiredo et al., "Cardiovascular risk in Japanese-Brazilian subjects," Arquivos Brasileiros de Endocrinologia and Metabologia, vol. 56, no. 9, pp. 608-613, 2012.

[24] A. Schienkiewitz, G. B. Mensink, and C. Scheidt-Nave, "Comorbidity of overweight and obesity in a nationally representative sample of German adults aged 18-79 years," BMC Public Health, vol. 12, p. 658, 2012.

[25] A. R. Doro, S. G. A. Gimeno, A. T. Hirai, L. J. Franco, and S. R. G. Ferreira, "Analysis on the association of physical activity with metabolic syndrome in a population-based study of Japanese-Brazilians," Arquivos Brasileiros de Endocrinologia and Metabologia, vol. 50, no. 6, pp. 1066-1074, 2006.

[26] M. Gatineau and S. Mathrani, Obesity and Alcohol: An Overview, National Obesity Observatory, Oxford, UK, August 2017, http://www.noo.org.uk/NOO_pub/briefing_papers.

[27] M. Q. Waleh, "Impacts of physical activity on the obese," Primary Care: Clinics in Office Practice, vol. 43, no. 1, pp. 97-107, 2016. 


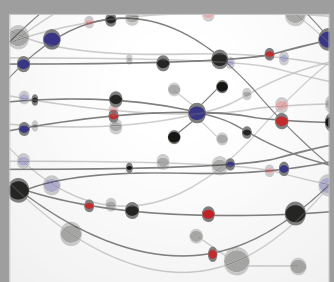

The Scientific World Journal
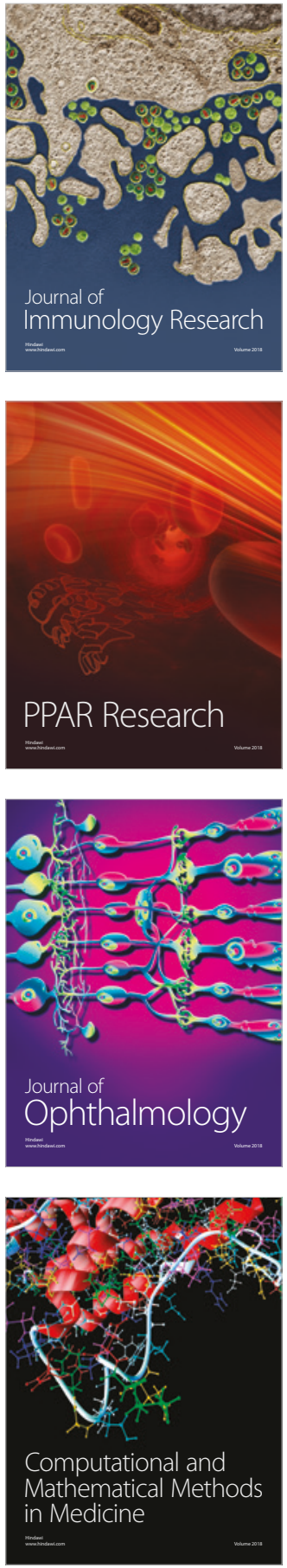

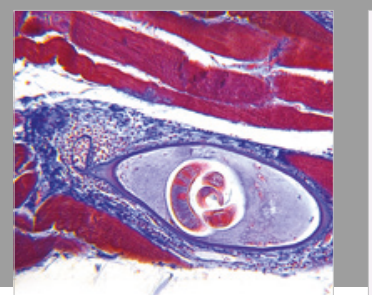

Gastroenterology Research and Practice

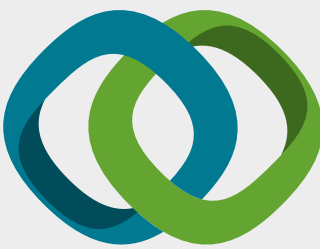

\section{Hindawi}

Submit your manuscripts at

www.hindawi.com
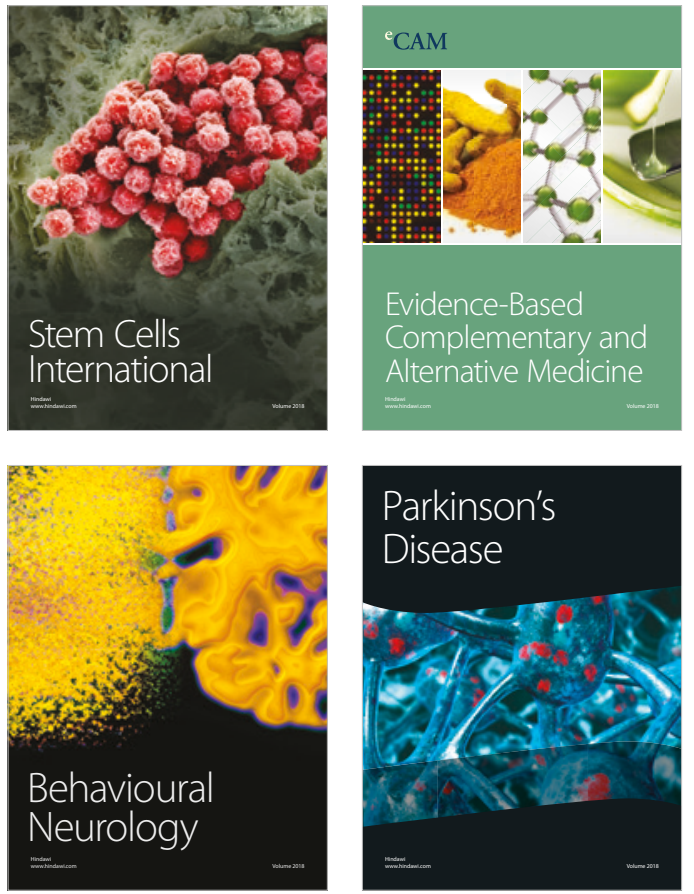



ournal of

Diabetes Research

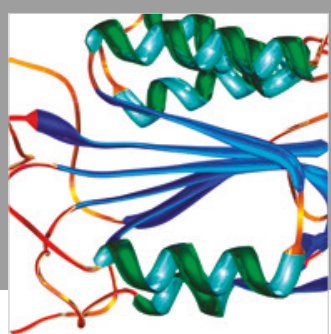

Disease Markers
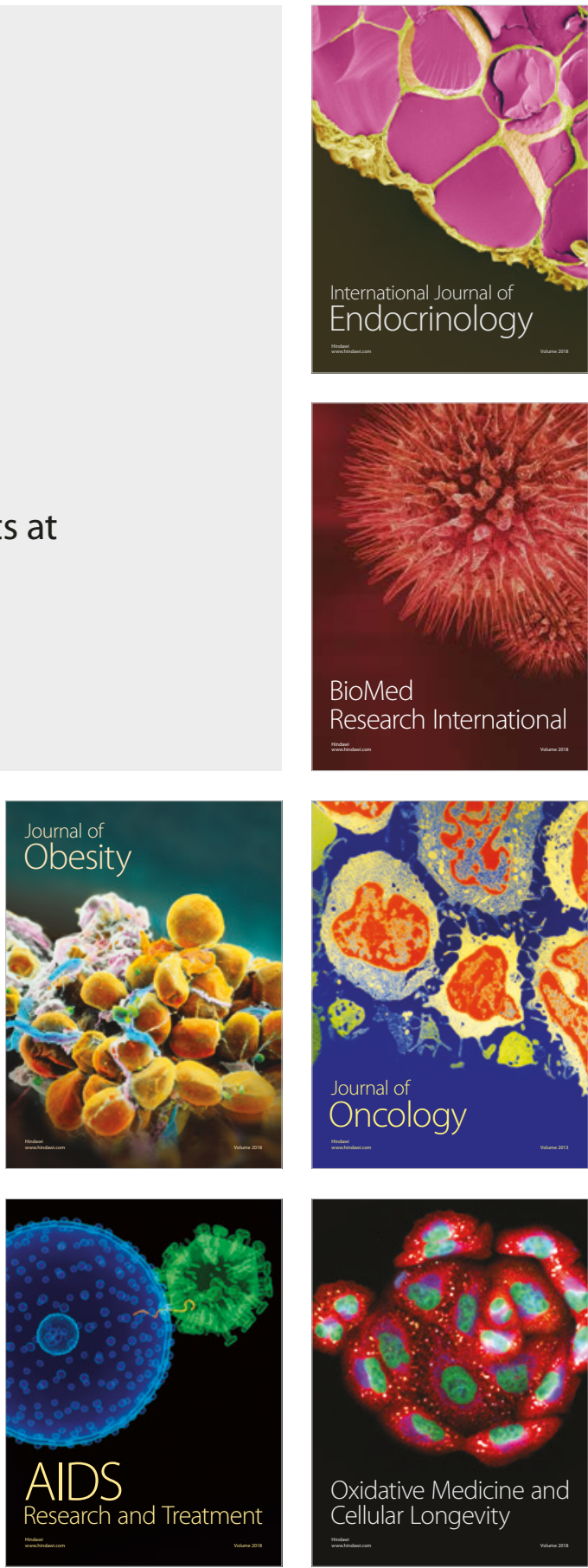